\title{
Essential Features of Eight Published Muslim Near-Death Experiences: An Addendum to Joel Ibrahim Kreps's "The Search for Muslim Near-Death Experiences"
}

\author{
Michael Nahm, Ph.D. \\ Freiburg, Germany \\ Joachim Nicolay, Ph.D. \\ Lemberg, Germany
}

\begin{abstract}
Among other authors, Joel Ibrahim Kreps (2009) has recently published accounts of Muslim near-death experiences (NDEs). With the present paper, we aim to contribute to the growing number of non-Western NDE reports by providing summaries of eight additional Muslim NDEs, seven translated from the original Italian source (Giovetti, 2007) and one from an English source (Lerma, 2009), and to provide references for further reading. In addition, we highlight noteworthy features of these eight summarized NDE accounts. Although the documentation standard of the available cases is generally low, these accounts indicate that the structure and contents of NDEs from many non-Western Muslim communities are largely similar to those reported in the Western NDE literature. In his report, Kreps concluded that Muslim NDEs are rare and that Muslims have fewer NDEs than do non-Muslim Westerners and non-Muslim non-Westerners such as the Chinese. However, we found that the number of Muslim NDE accounts available today seems to indicate that Muslim NDEs are not as rare as Kreps concluded.
\end{abstract}

KEY WORDS: Muslim near-death experiences (NDEs); non-Western NDEs; Western NDEs; shared NDEs, similarity and prevalence of NDEs.

Michael Nahm, Ph.D., is a biologist. After conducting research for several years in the field of tree physiology, he is presently concerned with developing improved strategies for harvesting woody plants for energetic use. He has a long-standing interest in unsolved problems of evolution and their possible relation to unsolved riddles of the mind. Joachim Nicolay, Ph.D. (philosophy), with diplomas in psychology, theology, and philosophy, is Deputy Chairperson of the Netzwerk Nahtoderfahrung/German Friends of IANDS. Correspondence regarding this article should be addressed to Dr. Nahm at Ida-Kerkovius-Straße 9, 79100 Freiburg, Germany; e-mail: michaelnahm@web.de. 
Recently, Allan Kellehear $(2008,2009)$ and John Belanti, Mahendra Perera, and Karuppiah Jagadheesan (2008) have presented crosscultural surveys on near-death experiences (NDEs). Kellehear limited his survey to the literature available to 2005, and Belanti, Perera, and Jagadheesan to 2004. In the meantime, additional sources from non-Western countries have become available. For example, James McClenon (2006) published an overview on Central and Southern African NDEs, Keith Augustine (2007) pointed to main findings of two Japanese NDE studies, Bryan Cuevas (2008) described Tibetan délok accounts previously not discussed in the NDE literature, J. Timothy Green (2008) published one report of a Hopi Indian NDE, and Joel Ibrahim Kreps (2009) presented an overview of his research on Muslim NDEs and included several examples. A few other authors have recently published additional accounts of Muslim NDEs. John Lerma (2009) described a Muslim NDE from Lebanon, and Jeffrey Long with Paul Perry (2010) presented examples of three more Muslim NDEs. Long and Perry also included in their book one NDE from Sudan and one from India, and Jeffrey Long with Jody Long published 24 more non-Western NDE accounts on their website (www.nderf.org), most stemming from India and from Muslim countries (Long \& Long, 2010).

In addition to these recently reported accounts are seven NDEs from Muslim countries that Italian physician and anesthetist Giorgio Fonzo from Foligno related to Paola Giovetti (2007). The cases that the Longs collected constitute a self-selected sample of writers who usually posted their NDE reports via the Internet; thus, their authenticity is difficult to evaluate. Basically, the same drawback applies to Giovetti's sample and many other collections, but at least Fonzo related only such cases to Giovetti that he claimed to have witnessed in person. To add to the growing number of non-Western NDE reports, in particular to the Muslim NDEs Kreps (2009) recently described, we summarize in this commentary the essential features of the seven NDEs Giovetti provided in Italian to make them available in English. Giovetti first published summaries of these NDE accounts in her book Qualcuno é tornato (1981a), but they were not included in a shortened version of the same book (1981b). The cases are reprinted again in her latest book on NDEs (2007), the source to which we refer in this article. In addition, we will briefly describe the Muslim NDE that Lerma (2009) reported. 


\section{Summaries of Muslim NDE Reports}

Fonzo worked from 1956 to 1964 for the Organizazzione Mondiale della Sanità in various Muslim countries. He stated that the accounts of the revived persons had left deep impressions in his memory. Thus, when he came across Raymond Moody's (1975) work many years later, he still remembered the accounts well and noted the similarity between them and the experiences Moody described. Following are summaries of the seven cases. Readers knowledgeable about research findings on NDEs are invited to compare the contents of the following cases to those findings; we will provide our observations on this topic in the Conclusion section of this article.

1. In his role as physician, Fonzo was responsible several times for accompanying pilgrimages to Mecca. The first of Fonzo's cases concerns a pilgrim by the name of Mustafa who fell into the ocean and "drowned" close to the Libyan coast (p. 126). After Fonzo had succeeded in reviving him, Mustafa reported that he had travelled through a tunnel and that he had seen a very bright but not blinding light. After that, he experienced a panoramic life review that was rich in details, particularly with regard to actions of beneficial and egotistical character.

2. The second case concerned a private patient who had suffered a cardiac arrest and was resuscitated by Fonzo (p. 126). After the man had overcome the health crisis, he claimed he had felt well, floating above his body with full consciousness and observing the resuscitation process. Apparently, all descriptions that the patient related corresponded to events as Fonzo had experienced them.

3. When Fonzo was director and anesthetist in a hospital in Yafran, Libya, he witnessed the following incident that also involved a cardiac arrest (p. 127). After a mother of five children, Loftia, was resuscitated, she stated she had seen, from above, a narrow passage with pillars painted white and blue on their tops. Fonzo explained that what she saw were in fact the gas bottles in the anesthesia center, stored in a narrow interspace between two walls to protect them from heating up. The tops of the gas bottles containing oxygen were colored white, and those containing nitrous oxide were colored blue. Fonzo maintained that these bottles were not visible to the patients. Furthermore, Loftia reported that she had met her deceased mother, Fatma. Her mother sent Loftia back, stating that Loftia had five children to care for-and that especially Nezahet, her two-year-old daughter, would need her care. For Loftia, returning to life was quite a negative experience. 
4. The fourth case took place during another pilgrimage to Mecca (p. 127). Fonzo was driving with two nurses to Cairo in a jeep, when they had an accident. Fonzo and one of the nurses remained uninjured, but the second nurse, a man, suffered a concussion and was unconscious. After Fonzo provided medical care, the man regained consciousness and described with "uttermost precision" what Fonzo and the other nurse had done during his moments of unconsciousness, including details of the resuscitation process. He also stated he entered a tunnel, but he didn't reach its end because a mufti, a religious teacher clothed in a white robe, gave him a sign to return. The nurse also reported that throughout the entire experience, his mind or consciousness had been connected to his physical body by a luminous cord, similar to a beam of light.

5. The fifth case tells the story of Muktar, a 12-year-old boy who fell from a palm tree and lay in a coma for some time (p. 128). After he regained consciousness, he reported having seen green grasslands, which came as a big surprise to him because he was familiar only with the yellow sand that surrounded his oasis village. He also talked of having heard music played without flutes and tambourines, instruments fundamental to the music of his local tradition. Muktar also recounted seeing an apparently bright light that he was able to look at without needing to protect his eyes. He added that he had met his grandfather and a younger brother of his, both deceased, and that he talked with them "without moving the mouth."

6. When Fonzo was working in a hospital in Beirut, a young man of 17 years had fallen from a high wall at the harbor and was severely injured and unconscious (p. 128). Fonzo and a nurse of the hospital, the uncle of the injured man, were immediately informed and hurried to the accident scene to provide him with medical care. During treatment, the young man came to himself for a few minutes and then died. He claimed that he had been able to see well during the time that his helpers hastened towards him and that his uncle at one point was in danger of falling himselfapparently a veridical observation. He went on to explain that the uncle was saved from falling only by the intervention of the uncle's deceased mother. While the young man related these visions, he claimed to see this woman again, who called for him, after which he expired.

7. The seventh and last case in Fonzo's collection constitutes a distressing NDE (p. 129). Mohamud, a Libyan bandit who had committed robbery and murder, was to be executed by hanging at sundown. Because tradition would not allow for burials after sundown, Mohamud's body was to be buried the next day. However, Fonzo realized that the man had actually not died and 
resuscitated him. Mohamud reported that he had seen "a plough" from above. Fonzo explained that in between the walls of the fortress was an old and closed well equipped with a lever device that, when seen from above, indeed resembled a plough. Moreover, Mohamud found himself in a state of utter loneliness and desertion at a nebulous and gloomy location without any light.

Fonzo was impressed by the fact that some features the near-death experiencers (NDErs) related did not fit into usual afterlife expectations of the Muslim culture; at least one of the NDErs, the nurse who was injured at the car accident (case 4), was considerably bewildered by this discrepancy. Examples of such cultural discordance include the tunnel and the light experiences, out-of-body experiences (OBEs), the religious figure sending the NDEr back, and, in the case of the distressing NDE, experiencing a profound loneliness instead of encountering tormenting demons as Muslims might expect. But also minor particulars puzzled Fonzo. For example, the 12-year-old boy who was surprised to see green grassland instead of yellow sand and to hear music that didn't feature familiar instruments, reported communicating telepathically with deceased family members-a faculty the boy may never have heard of. Because of these discrepancies with NDErs' cultural and personal belief systems, Fonzo concluded that these NDEs could not have been mere hallucinations (p. 130).

To conclude our collection of examples of Muslim NDEs, we briefly sketch the essential features of a case John Lerma reported. Lerma $(2007,2009)$ is a physician who has written about his experiences in hospice and palliative care. In his more recent book, he described this Muslim NDE:

Syriana, a Lebanese woman born into a wealthy and religious family, recounted how a missile hit their house when the family was getting ready to eat. After the explosion, all five family members had left their bodies and floated upwards into a tunnel of light where they met deceased relatives. They communicated telepathically with each other, and were informed that Syriana and her father were to return. Within a second, both found themselves back in their bodies under the table in their now destroyed home. Apparently, both remembered this episode, thus providing an example of a special type of shared NDEs. (Lerma, 2009, p. 194)

Although the way Lerma has presented his cases will satisfy only uncritical minds, they include many interesting reports that nevertheless might describe real episodes. 


\section{Concluding Remarks}

As mentioned in the introduction, it is difficult to judge the authenticity and reliability of the cases we presented. Fonzo's NDE accounts were obviously written down from recollection after several yearsand only after Fonzo had become familiar with Moody's (1975) research. Moreover, readers of this material learn almost nothing about possible Western influences that might have affected the NDErs previously in their lives; indeed, with the exception of one Libyan NDEr, Mohamud (case 7), not even the nationalities of the NDErs were specified. At least, it seems likely that the protagonists of cases 1,3 , and 4 were also Libyan and that the young man who fell from the high wall (case 6) was Lebanese.

Yet, despite these uncertainties and drawbacks, Fonzo's cases deserve consideration-if only to stimulate collecting further NDE reports from Muslim countries and to compare them to those already available. Fonzo's cases might indeed represent typical NDEs of that culture. The similarity of the reports that Kreps (2009), Lerma (2009), Long and Perry (2010), and Long and Long (2010) have published seems to support this notion, although these authors also did not provide much background information regarding possible Western influences on the Muslims reporting these cases.

We believe the case Lerma (2009) reported warrants particular attention, because it represents a type in which two or more persons in critical states of health share an NDE and return to tell an identical tale. To date, researchers have published only a few accounts of this kind. For example, Arvin Gibson (1999) described a case in which the 40 members of a fire-fighting unit met with an unexpected change of wind on a mountain slope. Struggling to breathe, one after another collapsed. Eventually, they all survived the crisis. Unfortunately, only one of the men was interviewed. He reported that upon collapse, they all rose above their physical bodies, were able to perceive the others hovering above their bodies, and communicated among each other. May Eulitt and Stephen Hoyer (2001) reported how three persons simultaneously struck by lightning experienced a shared NDE and survived. A few other authors have published or discussed examples of shared death or near-death experiences (Howarth \& Kellehear, 2001; Moody, 2010; Nahm, 2010). Despite the dearth of such cases, we consider them important and hope future researchers will remain alert for reports of them. 
In general, Lerma's (2009) and Fonzo's (Giovetti, 2007) NDE accounts appear similar to typical Western NDEs (Zingrone \& Alvarado, 2009) and to other published Muslim NDE reports. Four of Fonzo's seven reports (cases 2, 3, 4, 7) contain references to OBEs and to apparently non-physical veridical perceptions (AVPs). One of these OBEs (case 4) included the description of a luminous cord that connected the NDEr to his physical body during the OBE; this feature is rarely reported in contemporary NDE reports (for a classical case report of this sort, see Wiltse, 1889). Three accounts (cases 3, 5, 6) contained encounters with deceased family members. One of these (case 6) also included a pre-death vision; this case illustrates the close interrelation between NDEs and so-called deathbed visions (e.g., Fenwick \& Brayne, 2010; Osis \& Haraldsson, 1997)—visions that dying people sometimes have in the state of nearing-death awareness (Callanan \& Kelley, 1997) shortly before their deaths. Another of these encounter cases (case 5) involved telepathic communication with the deceased; this case also involved a preternatural environment and unearthly music. One of the seven NDErs (case 4) reported being sent back to life by a superior holy being, a mufti in a white robe. Fonzo also recounted a distressing NDE (case 7) that shares many similarities with Western distressing NDEs (Bush, 2009). Two of his reports (cases 1,4) contained mention of tunnel sensations, with the tunnel in one report (case 1) ending in a very bright but not blinding light, followed by a detailed panoramic life review. Another NDEr (case 5) also mentioned a very bright but not blinding light.

In this addendum to Kreps's (2009) paper on Muslim NDEs, we have presented summaries of eight additional NDE accounts from Muslim countries and provided references for further reading (Long \& Long, 2010; Long \& Perry, 2010). Kreps also described the difficulties he encountered in his search for Muslim NDE reports. He concluded that Muslim NDEs are quite rare and that Muslims tend to experience fewer NDEs than do non-Muslim Westerners and non-Muslim non-Westerners such as the Chinese. Although we acknowledge the poor documentation standard of the sources introduced in our commentary, it is our impression that the present state of research into Muslim NDEs permits a tentative twofold conclusion:

1) The structure and contents of the published Muslim NDE accounts seem largely similar to those of Western NDEs.

2) Muslim NDEs might not be as rare as Kreps (2009) concluded. 
However, it is clear that only systematic research into the contents and prevalence of Muslim NDEs will allow for arriving at a firm conclusion regarding these questions.

\section{References}

Augustine, K. (2007). Psychophysiological and cultural correlates undermining a survivalist interpretation of near-death experiences. Journal of Near-Death Studies, 26, 89-125.

Belanti, J., Perera, M., \& Jagadheesan, K. (2008). Phenomenology of neardeath experiences: A cross-cultural perspective. Transcultural Psychiatry, 45, 121-133.

Bush, N. E. (2009). Distressing Western near-death experiences: Finding a way through the abyss. In J. M. Holden, B. Greyson, \& D. James (Eds.), The handbook of near-death experiences: Thirty years of investigation (pp. 63-86). Santa Barbara, CA: Praeger / ABC-CLIO.

Callanan, M., \& Kelley, P. (1997). Final gifts: Understanding the special awareness, needs, and communications of the dying. New York, NY: Bantam Books.

Cuevas, B. J. (2008). Travels in the netherworld. Oxford, UK: Oxford University Press.

Eulitt, M., \& Hoyer, S. (2001). Fireweaver. Philadelphia, PA: Xlibris.

Fenwick, P., \& Brayne, S. (2010). End-of-life experiences: Reaching out for compassion, communication, and connection-Meaning of deathbed visions and coincidences. American Journal of Hospice and Palliative Medicine, published online before print: doi: 10.1177/1049909110374301.

Gibson, A. S. (1999). Fingerprints of God. Bountiful, UT: Horizon

Giovetti, P. (1981a). Qualcuno è tornato. Milan, Italy: Gruppo Editoriale Armenia.

Giovetti, P. (1981b). Qualcuno è tornato. Milan, Italy: Armenia Editore.

Giovetti, P. (2007). Near-death experiences. Testimonianze di esperienze in punto di morte. Rome, Italy: Edizioni Mediterranee.

Green, J. T. (2008). The death journey of a Hopi Indian: A case study. Journal of Near-Death Studies, 26, 283-293.

Howarth, G., \& Kellehear, A. (2001). Shared near-death experiences and related illness experiences: Steps on an unscheduled journey. Journal of Near-Death Studies, 20, 71-85.

Kellehear, A. (2008). Census of non-Western near-death experiences to 2005: Overview on the current data. Journal of Near-Death Studies, 26, 249-265.

Kellehear, A. (2009). Census of non-Western near-death experiences to 2005: Observations and critical reflections. In J. M. Holden, B. Greyson, \& D. James (Eds.), The handbook of near-death experiences: Thirty years of investigation (pp. 135-158). Santa Barbara, CA: Praeger / ABC-CLIO.

Kreps, J. I. (2009). The search for Muslim near-death experiences. Journal of Near-Death Studies, 28, 67-86.

Lerma, J. (2007). Into the light. Franklin Lakes, NJ: Career Press.

Lerma, J. (2009). Learning from the light. Franklin Lakes, NJ: Career Press.

Long, J., \& Long J. (2010). Non Western NDEs. Retrieved from http://www.nderf. org/non_western_ndes.htm 
Long, J., \& Perry, P. (2010). Evidence of the afterlife. New York, NY: HarperOne.

McClenon, J. (2006). Kongo near-death experiences: Cross-cultural patterns. Journal of Near-Death Studies, 25, 21-34.

Moody, R. (1975). Life after life: The investigation of a phenomenon-survival of bodily death. Atlanta, GA: Mockingbird Books.

Moody, R. (2010). Glimpses of eternity. New York, NY: Guideposts.

Nahm, M. (2010, in press). Reflections on the context of near-death experiences. Journal of Scientific Exploration.

Osis, K., \& Haraldsson, E. (1997). At the hour of death (3rd ed.). Norwalk, CT: Hastings House.

Wiltse, A. S. (1889). A case of typhoid fever with subnormal temperature and pulse. Saint Louis Medical and Surgical Journal, 57, 355-364.

Zingrone, N. L., \& Alvarado, C. S. (2009). Pleasurable Western adult near-death experiences: Features, circumstances, and incidence. In J. M. Holden, B. Greyson, \& D. James (Eds.), The handbook of near-death experiences: Thirty years of investigation (pp. 17-40). Santa Barbara, CA: Praeger / ABC-CLIO. 